\title{
SYSTEMATIC EMPIRICAL INVESTIGATION OF VULNERABILITY TO POSTPARTUM DEPRESSION FROM A PSYCHODYNAMIC PERSPECTIVE Commentary on Issues Raised by Blum (2007)
}

\author{
Avi Besser, $\mathrm{PhD}$ \\ Sapir Academic College
}

\author{
Nicole Vliegen, $\mathrm{PhD}$ and \\ Patrick Luyten, $\mathrm{PhD}$ \\ University of Leuven
}

\author{
Sidney J. Blatt, $\mathrm{PhD}$ \\ Yale University
}

In a recent paper, Lawrence Blum (2007) identified emotional conflicts in three areas typical in postpartum depression: (1) dependency, (2) aggression, and (3) motherhood. In this commentary, the authors consider agreements and disagreements with Blum's views on the psychodynamics of postpartum depression. In contrast to Blum's assertion, a theoretically derived extensive empirical psychoanalytic database exists which confirms and extends Blum's analysis of the core dynamics involved in this disorder. This recent research derives primarily from the comprehensive theoretical framework proposed by Blatt $(1974,2004,2006,2008)$ on the psychodynamics of depression that are part of a broad theory of normal and pathological personality development which Blum (2007), in his otherwise thorough search of the literature, seems to have overlooked. The authors close with reflections on how psychoanalysis and psychodynamically inspired research might increasingly influence mainstream clinical practice and research.

Keywords: psychoanalytic theories, postpartum depression, transition to motherhood, personality, self-criticism

In a thoughtful analysis of the psychodynamics of postpartum depression (PPD), Blum (2007) discussed emotional conflicts in three areas typical of this clinical condition: (1)

Avi Besser, PhD, Sapir Academic College, Israel; Nicole Vliegen, PhD and Patrick Luyten, PhD, University of Leuven, Belgium; and Sidney J. Blatt, PhD, Yale University, New Haven, CT.

Correspondence concerning this article should be addressed to Avi Besser, $\mathrm{PhD}$, Department of Behavioral Sciences, Sapir Academic College, D. N. Hof Ashkelon 79165, Israel. E-mail: besser@mail.sapir.ac.il 
dependency, (2) aggression, and (3) motherhood. He also noted that psychoanalytic concepts currently play only a minor role in contemporary research and treatment of PPD because it "has received little notice in the psychoanalytic and psychodynamic literature" (Blum, 2007, p. 46). Blum (2007) also noted a paucity of systematic empirical research on PPD from a psychodynamic point of view, citing a study by Menos and Wilson (1998) that "appears to be the only empirical study of psychoanalytic ideas in postpartum depression" (Blum, 2007, p. 52).

Blum's analysis is correct in many respects. Psychoanalytic views play a minor role in mainstream theory, research, and treatment of PPD. A search of the psychoanalytic literature using the descriptive label of "postpartum depression" and related concepts (e.g., postpartum blues) indeed yields very few papers. The Psychoanalytic Electronic Publishing (PEP) database, for example, yields only two articles; a case study by Harold Blum (1978) and a theoretical paper with an illustrative clinical vignette by Halberstadt-Freud (1993).

It is our belief, however, that Blum (2007) may have been misled by searching the psychoanalytic literature using the descriptive label of "postpartum depression." We demonstrate that a conceptually and empirically rich psychoanalytic literature exists concerning PPD that confirms and extends Blum's clinical and conceptual analysis of the core dynamics of this disorder. In particular, we argue that Blum has underestimated the contribution of psychoanalytic theory, research and treatment of PPD because these contributions have generally not been based on descriptive categorical diagnostic labels such as PPD, but on developmental analyses of adaptive and maladaptive outcomes in the transition to motherhood (e.g., Besser, Priel, \& Wiznizer, 2002; Priel \& Besser, 2000a, 2001, 2002; Raphaël-Leff, 1986, 2001; Stern, 1995); outcomes that include, but are not limited to, the clinical disorder of postpartum depression (Besser \& Priel, 2003a; Besser, Priel, Flett, \& Wiznizer, 2007; Priel \& Besser, 1999, 2000a; Vliegen, Luyten, Meurs, \& Cluckers, 2006). Likewise, we discuss psychoanalytically based treatment for mothers in postpartum psychological distress (e.g., Beebe, 2003; Cramer, 1997; Espasa, 2004; Fraiberg, 1980; McDonough, 2000; Shirilla \& Wheatherston, 2002; Tracey, 2000). Much of this more recent research derives from a comprehensive theoretical framework proposed by Blatt concerning the psychodynamics of depression (Blatt, 1974, 1990, 1992, $1998,2004)$ that is part of a broader theory of normal and pathological personality development (Blatt, 2006, 2008; Blatt \& Blass, 1990, 1996; Blatt \& Shichman, 1983). We discuss empirical research derived from this theoretical perspective that Blum (2007), in his otherwise thorough search of the literature, seems to have overlooked, perhaps because it has been published predominantly in nonpsychoanalytic journals. We also consider the implications of these empirical findings for Blum's views on the psychodynamics of PPD. We close with reflections concerning research in psychoanalysis, and particularly how psychoanalysis might increase its influence on mainstream clinical practice and research.

\section{The Transition to Motherhood From a Psychodynamic Perspective}

As Blum (2007) notes, the transition to motherhood is an important and complex developmental period in the life of a woman (Cowan \& Cowan, 1992; Raphaël-Leff, 2001; Stern, 1995). Psychoanalytic approaches emphasize that few experiences in a woman's life have more transformative power than pregnancy and motherhood (Cohen \& Slade, 2000). These transformative experiences described in the psychoanalytic literature can lead to considerable conflict and distress when they, depending on other factors, are 
not properly negotiated, including redefining self and other and containing ambivalence, factors that have a pivotal role in Blum's (2007) formulations of the dynamics of PPD. We briefly summarize psychoanalytic thinking and research concerning these dimensions, and elaborate them further based on research derived from Blatt's views on depression.

\section{Redefining Self and Other}

Both clinical theory (Raphaël-Leff, 2001; Stern, 1995) and research findings (e.g., Hopkins, Marcus, \& Campbell, 1984) suggest that the transition to motherhood requires a redefinition of self and other, heralding the beginning of a dramatic reorganization across a number of spheres in a woman's life including transformation of her relationship with her body, significant others, the culture, and her concept of self (Cohen \& Slade, 2000).

Psychoanalytic theory about the transition into motherhood began in the 1950s. The first psychoanalytic papers on the dynamics of pregnancy by Grete Bibring (e.g., Bibring, 1959; Bibring, Dwyer, Huntington, \& Valenstein, 1961) Kestenberg (1956) and Benedek (e.g., Anthony \& Benedek, 1970; Benedek, 1959) all noted the need to redefine self and others as intrinsic to pregnancy. Furthermore, Winnicott's (1956) concept of 'primary maternal preoccupation' proved to be crucial in understanding the intense affective changes in maternal psychic functioning after child birth, as is also evidenced by more recent psychoanalytically inspired research by Leckman, Mayes and others which addressed differences between mothers and fathers in parental preoccupations (Leckman \& Herman, 2002; Leckman et al., 1999, 2004), and their role in buffering PPD (Leckman, Feldman, Swain, \& Mayes, 2007). Ferber and Feldman (2005), for instance, found that mothers whose preoccupations concerned themselves and their pain and discomfort, instead of the baby, showed higher levels of anxiety and depression 6 weeks postpartum.

Denora Pines (1972) subsequently drew attention to the interaction between fantasy and reality in pregnancy and early motherhood. She also addressed topics such as miscarriages and abortion (e.g., Pines, 1990) as well as adolescent pregnancy and motherhood (Pines, 1988). Feder (1980) addressed ambivalence during pregnancy, whereas Raphaël-Leff (1982) considered the psychotherapeutic needs of future mothers, a theme she elaborated further in her work on therapeutic interventions in the postpartum period (Raphaël-Leff, 2000). More recently, psychoanalytic authors have focused on the psychological work that has to be done during pregnancy and the earliest stages of parenthood. Brazelton and Cramer (1991), for example, consider the fantasies about the fetus as the 'prehistory of attachment' that underline the processing that future parents have to do during pregnancy. We will return to these issues in our discussion of relevant psychoanalytically inspired research.

The transition to motherhood also includes important role changes and a redefinition of significant relationships, including consideration of child care and career, which may question one's personal and social identity (Brooks-Gunn \& Chase-Lansdale, 1995). Stern (1995) notes that with the birth of a baby, the mother passes into a new and unique psychic organization, the "motherhood constellation," that involves openness or a close connection with unconscious representations and processes, with feelings and experiences that at other moments in life are often ignored. According to Raphaël-Leff (1986, 2001), the reprocessing of old conflicts is one of the major psychological tasks of child bearing, a reprocessing that Stern (1995) notes involves four important concerns: the life-growth theme (can I maintain the life and growth of the baby?), the primary relatedness theme (can I emotionally engage with the baby in an authentic manner, and assure the baby's psychic development?), the supporting matrix theme (can I create and maintain the 
necessary support system to fulfill these functions?), and the identity reorganization theme (am I able to transform my self-identity to permit and facilitate these functions?).

Thus, childbirth and the need to reorganize conscious and unconscious aspects of representations of self and others may reactivate unprocessed experiences, such as loss and mourning (Raphaël-Leff, 2001). Childbirth can confront the mother quite suddenly, for example, with unprocessed affects concerning the loss of her own mother when she was a child, or concerning a sad and depressed mother when a sibling or another family member died, or the bad, unavailable and neglectful mother she had as a child. Likewise, a mother who previously had a miscarriage may feel intensely happy with her new baby, but at the same time experience feelings of depression related to her previous miscarriage or anxiety about the possibility of another loss. These are but a few examples of difficult emotional experiences that can be aroused when becoming a mother that illustrate the importance of schemas (internal working models) in the postpartum period which are rooted in early attachment experiences.

Psychoanalytically oriented research supports the important role of early attachment experiences and internal working models in the postpartum period and for PPD in particular. Besser, Priel, and Wiznizer (2002), for example, explored the effects of interactions between pregnancy risk, perceptions of social support, and internal working models related to attachment on PPD in women with low $(n=103)$ and high $(n=110)$ risk pregnancies. Both attachment to and social support from the spouse reduced depressive symptoms in childbearing. The extent of this effect, however, varied according to the pregnancy risk conditions. Although increased health risk had a negative effect on all mothers, those with more positive models of attachment were significantly more resilient, especially when the health risk was high.

In a subsequent study of 120 pregnant women, Priel and Besser (2002) explored the impact of perceptions of available and effective social support on three outcome variables: postpartum depressive symptomatology (PPD), the newborn's APGAR (i.e., rates of Appearance [color]; Pulse [heartbeat]; Grimace [reflex]; Activity [muscle tone]; and Respiration [breathing], Nelson, 1987) scores, and mother's perceptions of her baby. They found that, as expected, social support mediated the relationship between new mothers' perceived early relationships with their own mothers and the occurrence of PPD, perceptions of the infant, and the newborns' APGAR scores. ${ }^{1}$ Interestingly, Priel and Besser $(2000,2001)$ also found that attachment styles and object relations tapped related, but not identical, constructs. In particular, they found that the relationship between pregnant women's internal working models and antenatal attachment to their infant was mediated by the future mother's representations of her own mother. Hence, from a clinical perspective, early attachment as well as current object relations both seem to express related, but not identical, aspects of internal working models (Besser \& Priel, 2007; Priel

${ }^{1}$ The mediating role played by social support in the association between mothers' perceptions of early relationships and the newborn's APGAR scores suggests that mother-infant interactions might take place, on a somatic level, already before birth (Benoit et al., 1997; Priel \& Besser, 2000a). Higher maternal distress levels may explain the relation of newborn's health status at birth is related to physiological concomitants of the mothers' affective state. This explanation is corroborated, to some extent at least, by studies of the intrauterine effects of maternal anxiety that report significant associations between maternal emotionality and APGAR scores (Ponirakis et al., 1998), and between prenatal maternal anxiety and attention deficit hyperactivity disorder symptoms, externalizing problems, and self-reported anxiety at age 8 and 9, as well as impulsivity during performance on cognitive tasks at age 14 and 15 (Van den Bergh et al., 2004, 2005). 
\& Besser, 2001) that have an important impact on postpartum adaptation. Congruent with Blum's (2007) assumptions, these psychodynamically inspired studies suggest that mother's own early attachment experiences and her perceptions of her own caregivers influence her attachment to her child and that this association is mediated by the mother's representations of early caring relationships, especially with her own mother (Fonagy, Gergely, \& Target, 2007).

\section{Maternal Affective Dynamics: Containing Ambivalence, Distress, and Feelings of Anger; Empowering Love and a "Secure" Base}

Mothering is often associated with feelings of warmth, bliss, and tenderness. The transition to motherhood, however, is also characterized by negative affect, including feelings of sadness, loss, anxiety, and anger (Arendell, 2000). Intense feelings are a normal part of the postpartum period (Raphaël-Leff, 2001; Ruddick, 1994). Importantly, as noted by Blum (2007), both clinical descriptions and empirical studies suggest that depression in the postpartum period is also associated with elevated levels of anger and anger attacks (Beck, 1996, 2002; Hagen, 1999; Weinberg \& Tronick, 1998). Hoffman (2003) points out that many young mothers experience conflicts over aggression and become intolerant of their ambivalence toward their child. In this context, Beck (1996) found that "uncontrollable anger" was an important recurring theme in PPD. Born and Steiner (1999) called irritability and proneness to anger 'the forgotten dimension of female specific mood disorders', including perinatal mood disturbances. Likewise, Mammen, Shear, Pilkonis, Kolko, Thase, and Greeno (1999) noted the lack of recognition of anger as a particular problem among mothers, possibly because women are socialized to deny and disavow anger. Because high levels of parental anger can have detrimental effects on child development (Cummings \& Davies, 1994), recognizing and treating problems of anger and anger regulation in the postpartum period may be helpful for mothers and their children (Mammen et al., 1999).

Despite its potential importance, surprisingly few studies have examined the role of anger in postpartum depressed mothers. Several studies in this area, however, extend Blum's (2007) clinical observation about the importance of aggression in postpartum depression. Rosenblum, Mazet, and Bénony (1997), for example, were able to classify postpartum depressed mothers in two categories, as either "dull and slow" or as "stressed and irritable." The first group expressed complaints such as "concentration difficulties, weariness and inability to feel,' the latter reported 'inner tension, little sleep and pessimism.'

Depression in both types of depressed mothers was stable over the first 6 months postpartum and associated with different patterns of affective involvement. The issue of anger in PPD will be considered in more detail below in our discussion of research that distinguishes subtypes of depressed mothers based on Blatt's model of depression and how they differentially handle anger.

\section{Psychoanalytic Treatment and the Postpartum Period}

Although, as noted by Blum (2007), few systematic studies of psychoanalytic treatment of postpartum depression are available, there is a long tradition of psychoanalytic treatment of mothers and their infants, many of whom would be considered to have PPD. Fraiberg et al.'s (1975) paper on "ghosts in the nursery" is a milestone in this respect, followed by several other clinical case studies (e.g., Cramer, 1997; Espaca, 2004; 
Likierman, 2003; Shirilla \& Wheatherston, 2002; Tracey, 2000), and by more systematic descriptions of clinical work in the postpartum period (e.g., Beebe, 2005). Vliegen (2006), for example, described experiences with postpartum depressed mothers hospitalized with their infants and noted how important maternal feelings and thoughts were "easy to reach" even in a short, research-oriented contact. She also noted flexibility and openness in these mothers for new ways of thinking that is typical of early maternal development. In line with Emanuel (2006) and Watillon (1993), Vliegen (2006) noted rapid and impressive therapeutic effects in working with young children that resulted from the "dramatization" of experience. The conflict is "staged" as it were by mother and child. The accessibility of this dramatization highlights the value of a nonintrusive, nonjudgmental early intervention. Future research efforts should further explore these clinical experiences.

\section{Blatt's Two Primary Configurations Model}

The contributions of Blatt and colleagues to the understanding of depression provide a major psychoanalytic theoretical frame that has engendered research on PPD, contributions that Blum (2007) overlooked in his otherwise excellent review. Blatt and colleagues (Blatt, 2006, 2008; Blatt \& Blass, 1990, 1996; Blatt \& Shichman, 1983) view personality development as evolving through a hierarchical synergetic dialectic development of self-definition and interpersonal relatedness-"the development of a realistic, essentially positive and increasingly integrated self-definition and self-identity" and the development of "the capacity to establish increasingly mature, reciprocal and satisfying interpersonal relationships" (Blatt, 1991, p. 453). These two basic modalities of human existence have been referred to earlier in different theoretical contexts as autonomy and surrender (Angyal, 1951), agency and communion (Bakan, 1966), and achievement or power versus affiliation or intimacy (McAdams, 1985; McClelland, 1985; Winter, 1973; see also Freud, 1930/1961).

An adequate balance between relatedness and self-definition contributes to an evolving self-sufficiency that, in turn, facilitates the establishment of stable interpersonal relationships (e.g., Blatt, 1974, 1990; Blatt \& Blass, 1996; Blatt, Quinlan, Chevron, McDonald, \& Zuroff, 1982; Blatt \& Shichman, 1983). Excessive emphasis on either one of these dimensions to the neglect of the other predisposes individuals to depression (Blatt \& Zuroff, 1992), including PPD (Blatt, 2004). Overemphasis on issues of relatedness (i.e., dependency, neediness) - is characterized by excessive preoccupation with the availability of love, nurturance, and support, and by a heightened need for closeness and interpersonal support. Exaggerated emphasis on issues of self-definition (i.e., self-criticism) is associated with harsh standards, heightened strivings for mastery and achievement, and a marked need for acknowledgment. Similar formulations have subsequently been proposed from other theoretical perspectives including Beck's (1983) differentiation of sociotropic and autonomous depression and Arieti and Bemporad's (1980) distinction between a dominant other and a dominant goal type of depression.

The validity of concepts of Dependency and Self-Criticism as important personality dimensions and as expressions of relatedness and self-definition, respectively, has been empirically demonstrated in research using the Depressive Experiences Questionnaire (DEQ) that assesses life experiences, rather than overt symptoms, of depressed individuals (Blatt, D'Afflitti, \& Quinlan, 1976). The first factor on the DEQ, Dependency, includes concerns about abandonment, helplessness and loneliness, and the need for close and dependent interpersonal relationships. The items loading on the second DEQ factor, Self-Criticism, reflect a continuous preoccupation with failure, ambivalent feelings about 
self and others, and a self-critical stance (Blatt et al., 1974). A considerable body of research has demonstrated that Self-Criticism as compared to Dependency involves greater vulnerability to depression as well as to other negative affects and distress (e.g., Besser, 2004; Besser, Flett, \& Davis, 2003; Besser \& Priel, 2003; Besser \& Priel, 2005a, 2005b; Blatt, 2004; Luyten, Corveleyn, \& Blatt, 2005; Nietzel \& Harris, 1990; Zuroff, Mongrain, \& Santor, 2004).

Self-definition and interpersonal relatedness develop initially in early parent-child relationship (Blatt, 1974; Blatt \& Homann, 1992). Negative parenting practices (i.e., neglectful or harsh and punitive judgmental standards) can interfere with the dialectic synergistic development and contribute to the child's development of dependent and self-critical vulnerabilities that can lead to two types of depression-an anaclitic and an introjective depression, respectively (for an overview, see Blatt, 2004). Besser and Priel (2005), for example, in a community sample of 300 participants (100 three-generation triads of women) found that Dependency and Self-Criticism were the basis for the relationship between insecure attachment and depression both within and across three generations. Their findings provide empirical documentation extending Blum's assertion that early childhood experiences, particularly insecure attachment, often play a central role in (postpartum) depression.

Moreover, issues of relatedness and self-definition are central in Blum's (2007) considerations of the psychodynamics of postpartum depression. This should hardly be surprising given the emphasis in the psychoanalytic literature, as Blum noted, on the need to redefine self, other, and self-in-relation-to-others in the postpartum period. Unfortunately, however, personality factors have not been the subject of extensive investigation, thus causing Swendsen and Mazure (2000) to express their disappointment about the failure to more fully assess the role of cognitive and personality factors in PPD. In contrast, Blatt's theoretical formulations and his two configurations model have provided several research groups with a comprehensive and integrative approach to research that enabled them to conduct systematic empirical investigations to examine more fully issues in the transition to motherhood and the occurrence of PPD. We briefly review these studies and how they confirm and extend Blum's clinical formulations.

\section{The Transition to Motherhood and Postpartum \\ Depression in the Context of the Two Primary \\ Configurations Model}

Based on Blatt's theoretical model, the transition to motherhood may be conceptualized as a challenging reassessment of issues of both self-definition and interpersonal relatedness (Antonucci \& Mikus, 1988; Belsky, Rowine, \& Fish, 1989; Gotlib \& Hooley, 1988; Ruble, Brooks-Gunn, Fleming, Fitzmaurice, Stangor, \& Deutsch, 1990; Whiffen \& Gotlib, 1993).

In a series of studies, Priel, Besser, and colleagues (Besser \& Priel, 2003a; Besser, Priel, Flett, \& Wiznizer, 2007; Priel \& Besser, 1999, 2000) as well as Franche and colleagues (Franche, 2001; Franche \& Mikail, 1999) found that Self-Criticism is consistently related to postpartum depressive symptoms, whereas Dependency seems to reduce the development of postpartum depressive symptoms. These conclusions, however, need to be qualified because the relations between Self-Criticism and Dependency and depressive symptoms after childbirth are affected by several factors including the quality of attachment to the unborn baby (Priel \& Besser, 1999), social support (Priel \& Besser, 
2000), coping skills (Besser \& Priel, 2003a), and stress during pregnancy (Besser et al., 2007). We briefly consider research relevant to each of these factors.

The mother's antenatal attachment to her unborn baby is a central developmental task in pregnancy and childbirth, and studies have shown that the mother's emotional attachment to her fetus during pregnancy is predictive of mother-infant relationships after birth (Fonagy, Steele, \& Steele, 1991; Priel \& Cantor, 1988). Maternal prenatal representations of the infant remain stable during pregnancy and later are related to the child's security of attachment (Benoit, Parker \& Zeanah, 1997; Condon, 1993; Fonagy et al., 1991). Moreover, recent investigations of therapeutic interventions with postpartum depressed mothers (Cramer, 1997) suggest a direct association between PPD and the quality of mother-infant relationships. Maternal depression and self-esteem were found to improve considerably after therapeutic interventions centered on the vicissitudes of the mother-infant relationships.

Priel and Besser (1999), in a longitudinal study of 73 pregnant women, hypothesized that prenatal bonding constitutes a protective factor for psychopathological reactions in the mother during pregnancy and after childbirth. In the context of the Dependency/SelfCriticism vulnerability model, they assumed that the capacity to establish an attachment to the fetus enhances the pregnant women's self-esteem and feelings of competence, thus moderating the vulnerability to PPD, especially among self-critical women. They assumed that self-critical women are likely to become increasingly self-critical when facing motherhood, a role different from anything they had experienced before. In addition, the limitations imposed by pregnancy and the demands of caring for an infant may compromise the self-critical woman's strong need for autonomy. These issues may not distress dependent mothers as much because these women may derive satisfaction from increased familial support during pregnancy and immediately after childbirth, as well as from providing care for their newborn baby. Results showed, as expected, that higher antenatal attachment to their infant predicted less postpartum depressive symptoms among selfcritical mothers, indicating the importance of the earliest bonding for these mothers. Thus, the preoccupation with a revised identity and the possible loss of freedom experienced by self-critical mothers can be compensated for if they have the capacity to establish an affectionate bond to their baby before birth. Hence, the facilitation of such an affective bond with the fetus in the antenatal period appears to be important in the prevention and treatment of postpartum depression in self-critical women.

In addition to antenatal attachment, social support has been shown to be another moderator in the association between Self-Criticism, Dependency, and PPD that may, in part, explain the differential relationship between these personality dimensions and depression in the postpartum period. Priel and Besser (2000), for example, in a prospective study of 121 pregnant women, found that Dependency in young mothers was positively associated with enlisting help from significant others, which led in turn to increased feelings of well-being. Self-Criticism, in contrast, was negatively associated with eliciting social support from significant others, which in turn led to higher levels of postpartum depressive symptoms. The association between Self-Criticism and decreased social support hints at a possible complex attitude that highly self-critical new mothers may have in getting needed assistance from significant others. Receiving help and support may be a mixed blessing for these self-critical women because it may be experienced as an indication of their failures and inadequacies or as limiting their autonomy. Interestingly, Priel and Besser (2000) also found that Dependency was more positively associated with obtaining specific help (i.e., from the husband) than with global social support, whereas Self-Criticism was more related to obtaining global (general) than specific support. 
These results of Priel and Besser (2000) suggest that Dependency does not necessarily imply passivity but it can include an important active interpersonal component, a form of instrumental approach (Cross \& Madson, 1997) expressed in active seeking and maintaining support that may be important in facilitating well-being in the transition to motherhood. Besser and Priel (2003a) further speculated that this interpersonal instrumentality may also be expressed in active coping styles associated with Dependency, whereas Self-Criticism can be expected to be associated with maladaptive avoidant modes of coping. Interestingly, studies have shown that mothers who use approach coping strategies have lower emotional distress than those relying on avoidant coping strategies (Colletta \& Gregg, 1981; Terry, 1991; Terry, Mayoccuni, \& Hynes, 1996).

Consistent with these theoretical formulations, Besser and Priel (2003a), in a longitudinal study of 146 pregnant women, found that Dependency was associated with low avoidant and high approach coping, whereas Self-Criticism was related to low approach and high avoidant coping strategies. In addition, approach coping strategies moderated the deleterious effects of Self-Criticism on depressive mood after childbirth. Although selfcritical mothers tended not to use approach coping strategies, when they did use them, these mothers were significantly less depressed. Another, perhaps complementary, explanation of these results suggests that the effect of approach coping strategies in self-critical mothers may be characteristic of those individuals who have more flexible ways of coping with distress-more high-functioning self-critical mothers characterized by a fuller integration of self-definition and interpersonal relatedness (Blatt, 1998, 2006, 2008; Blatt \& Blass, 1990, 1996; Blatt \& Shichman, 1983; Blatt \& Zuroff, 1992).

The studies summarized thus far indicate a potential interaction between dependent and self-critical personality dimensions and stressful experiences in the postpartum period. Although much more research is needed, a longitudinal study by Besser et al. (2007) addressed this issue in low $(n=109)$ and high $(n=100)$ stress pregnancies, examining both linear and nonlinear relationships of Self-Criticism and Dependency to PPD. Besser et al. (2007) speculated that linear associations would be characteristic of a low stress context, whereas under high stress, nonlinear associations would occur because the stress may activate latent dependent and self-critical cognitive schemas, contributing to a nonlinear association between personality vulnerabilities and depression. Hence, under higher levels of stress, even small increases in personality vulnerabilities were expected to be associated with large changes in the severity of depressive symptoms (Brown \& Harris, 1978).

Results confirmed Besser et al.'s expectations, corroborating a transactional perspective between personality vulnerabilities and degree of situational stress (Lazarus, 1999). It seems that the magnitude of situational demands do not directly determine the expression of symptoms of stress because individual differences in coping abilities and vulnerabilities may have a magnifying impact among individuals (the accentuation principle), underscoring the need to investigate the interactions between the environment and the person as an active agent (Luyten, Blatt, Van Houdenhove, \& Corveleyn, 2006; Shahar, 2006; Zuroff, Mongrain, \& Santor, 2004).

Finally, Besser et al. (2007) found another important nonlinear effect indicating that under low and high levels of stress, but not under intermediate levels of stress, Dependency no longer functioned as a resilience factor, but in fact created a vulnerability to depressive symptoms in the postpartum period. In stressful life contexts, very low and high levels of Dependency may limit the ability of dependent women to enlist and maintain social support and effectively use adaptive coping strategies (Besser \& Priel, 2003a; Priel \& Besser, 2000), but possibly for different reasons. Low Dependency likely 
involves a lack of connectedness and meaningful involvement with others, whereas high Dependency may result in unreasonably high demands for care and extreme neediness that leads to interpersonal conflict and decreases in level of social support. Among high-risk pregnant women, only moderate levels of Dependency were associated with the ability to efficiently elicit and use social support which facilitated coping (Cohen, 1993). Further research is needed to investigate these assumptions, some of which we review further in the next section.

\section{Further Studies on the Two Configurations Model}

Blatt's theoretical model has clearly led to a productive research program on postpartum depression. These studies confirm and extend Blum's clinical observations concerning the psychodynamics of PPD. At the same time, many questions remain. First, all previous studies based on Blatt's two configurations model focused on relatively normal community mothers. Hence, the question remains whether these findings generalize to clinical samples. For instance, as noted above, in the study of mothers with high-risk pregnancy (Besser et al., 2007), low and high levels of Dependency were a vulnerability factor for the development of postpartum depressive symptoms, implying that Dependency may also be related to PPD but in complex curvilinear ways. Likewise, Boyce, Parker, Barnett, Cooney, and Smith (1991), found that interpersonal sensitivity, a core characteristic of Dependency, was associated with increased probability of PPD, illustrating the need for further research on and the conditions in which Dependency and Self-Criticism may be adaptive or maladaptive. Second, Blum (2007) makes a strong case for the role of aggression and other negative emotions (such as anxiety) in the dynamics of PPD. In this context, dependent and self-critical mothers would be expected to differ in the way they express and deal with anger, anxiety and other negative emotions.

Several studies currently underway address these important questions. Vliegen, Luyten, Meurs, and Cluckers (2006), for example, focused upon the role of adaptive and maladaptive personality dimensions associated with self-definition and relatedness in nonclinical mothers. Congruent with findings from a number of previous studies (e.g., Franche, 2001; Priel \& Besser, 1999, 2000), Self-Criticism was associated with severity of depression in the postpartum period in both primiparous and multiparous mothers, extending previous findings with multiparous mothers. As in previous studies, Dependency was not associated with severity of depression. Dependent mothers may experience having a baby as fulfilling their strong needs for relating and caring and not be as concerned with relinquishing some professional or social goals.

When Vliegen and colleagues differentiated between adaptive versus maladaptive dimensions related to self-definition (Efficacy and Self-Criticism, respectively) and to interpersonal relatedness (Relatedness and Neediness, respectively) as measured with the DEQ, they found, as expected, that Self-Criticism, but not Efficacy, was associated with severity of depression. These findings lend further support to the view that Self-Criticism is a particularly maladaptive personality dimension, associated with psychological distress, whereas Efficacy, a more adaptive dimension of self-definition, is essentially unrelated to distress (Blatt et al., 1995). Results concerning adaptive and maladaptive levels of interpersonal relatedness (Dependency) were more complex. Contrary to expectations, the more adaptive dimension, Relatedness, but not Neediness (the more maladaptive dimension of interpersonal relatedness), was associated with depressive symptoms. These findings suggest that the more adaptive level of dependency, Relatedness, is associated with distress in normal community mothers, possibly because healthy related- 
ness implies appropriate concerns about the baby's as well as one's own future. Levels of maladaptive neediness, however, were not associated with distress, probably because maladaptive neediness is associated with a denial of distress. In addition, in clinical samples with higher levels of neediness, different results may emerge. For instance, with increasing levels of Neediness, having a baby might be experienced as interfering with the fulfillment of dependent mother's own needs for care and support. In addition, giving birth and anticipating the baby's future wishes for separation and autonomy might be experienced as threatening because these women's strong needs for merger and union, thus leading to considerable distress.

To investigate these issues further, Vliegen and Luyten (2007a) studied the role of Self-Criticism and Dependency in a sample of depressed postpartum women. As expected, these mothers had higher levels of both Dependency and Self-Criticism than nondepressed young mothers, suggesting that both personality dimensions may be associated with postpartum distress, but in different ways. In nondepressed mothers, Self-criticism was related to the intensity of depressive symptoms as well as to feelings of anxiety, but in the postpartum depressed sample, Dependency was related to severity of depression whereas Self-criticism was associated with feelings of anxiety. Results of this study therefore indicate important differences in clinical and nonclinical samples in the relationships of Dependency to depression. Together with a number of other studies of nondepressed mothers (Besser \& Priel, 2003; Franche, 2001; Franche \& Mikail, 1999; Priel \& Besser, 1999, 2000), these results suggest that relatively low levels of Dependency may protect against feelings of postpartum depression, whereas higher levels of Dependency may be associated with postpartum depression. As noted by Priel and Besser (1999), in mothers with relatively low levels of Dependency, as is typical in community mothers, the new relationship with the baby provides the opportunity for caring for an other person, in ways in which one desires to be cared for oneself. However, in highly dependent mothers, who have more intense needs for merger and union, the baby may confront them with their own deep feelings of dependency as well as fears of loss and abandonment. Moreover, findings of Besser et al. (2007) suggest that mothers with extremely low levels of dependency might not be able to relate to their baby, and experience considerable distress and feelings of insufficiency over this inability. Thus, as suggested by Besser et al. (2007), there may be a curvilinear association between Dependency and PPD, but further research is needed to investigate this assumption.

In a more recent study, Vliegen and Luyten (in press) explored the relationship between anger and the Dependency and Self-Criticism dimensions in the postpartum period. Congruent with Blum's clinical observations, postpartum depressed mothers, compared to normal controls, had elevated levels of state and trait anger. Moreover, consistent with the traditional psychodynamic view, depression was associated with anger toward the self (Fisher \& Greenberg, 1996). Considerable variability, however, was noted in the relationship between anger and depression and the Dependency and Self-Criticism personality dimensions. In postpartum depressed mothers, Dependency was unrelated to levels of state and trait anger, indicating that postpartum depressed dependent mothers may have considerable difficulty acknowledging feelings of anger, suggesting that dependent mothers suppress (Gilbert, Gilbert, \& Irons, 2004) or deny anger (Blatt, 1974, 2004) or, when it is expressed, it is directed toward the self. These findings are congruent with Rosenblum et al.'s (1997) identification of postpartum depressed mothers they described as 'dull and slow,' and as expressing complaints about 'being not able to feel.'

In contrast, Self-Criticism was highly associated with levels of state and trait anger. Self-critical mothers also directed anger toward others as well as themselves, and reported 
a lack of control of their angry feelings, suggesting that self-critical mothers resemble the depressed mothers that Rosenblum et al. (1997) identified as irritable and stressed mothers, or the angry/hostile subtype of depression that has been identified in research on major depression (Luyten, Sabbe, Blatt et al., 2007; see also Bagby et al., 1997). Congruent with a number of studies on depression (see Luyten et al., 2007 for a summary), these findings indicate considerable variability in the relationship between depression, anger, and anger regulation, suggesting that clinicians need to attend to the impact of personality dimensions on the way postpartum mothers deal with anger.

Vliegen and Luyten (2007b) also found differential relationships between Dependency and Self-Criticism and experiences of positive and negative affect in depressed mothers. Self-Criticism was associated with an absence of positive emotion categories (joy, love) and the presence of negative emotions (i.e., sadness, fear, anger, and guilt/shame). Dependency, in contrast, was associated only with negative affect-with sadness, fear, and guilt/shame (Vliegen \& Luyten, 2007b). Although dependent mothers reported a lack of joyful feelings, they showed some capacity to experience feelings of love.

These findings extend in important ways Blum's (2007) views concerning the role of anger and other negative emotions in postpartum depression. Dependent postpartum depressed mothers may be more capable of experiencing feelings of relatedness that may play a constructive role in the relationship with their infants and their ability to establish and maintain social support. Furthermore, dependent mothers seem to experience less anger, which may also benefit their relationship with their infant. From a clinical perspective, in treatment one might seek to augment the dependent mother's ability to experience feelings of love toward her baby, feelings that could function as a buffer in a period of suffering and pain. Self-critical mothers, in contrast, seem to need assistance in overcoming their inability to experience feelings of love because of their feelings of guilt, shame, and anger-feelings that contribute to their tendency to disengage from their infant and from their sources of interpersonal support because of their avoidant coping style (Beebe et al., 2007).

Overall, these recent studies lend further support to the important role of the personality dimensions of self-definition and interpersonal relatedness in the postpartum period, suggesting that clinicians need to attend to these personality dimensions in young mothers. Future research, of course, is needed to replicate these findings and to investigate further the influence of Dependency and Self-Criticism on affect regulation between mother and child in longitudinal, multi-informant research with clinical and nonclinical samples. In particular, observational studies are needed to study the impact of the mother's personality dimensions of Dependency and Self-Criticism on the interaction between mother and baby in depressed and nondepressed mothers. Several of these studies are currently underway (Beebe et al., 2007; Vliegen \& Luyten, 2007c), studies that promise to lead to new insights into the processes involved in postpartum depression and in the transmission of depressive affect between mother and child.

\section{Discussion}

We agree with Blum's (2007) call for more research from a psychodynamic perspective on PPD. Although in recent years much empirical research has been done on issues of depression in the postpartum period, important questions remain. In addition to longitudinal, multi-informant studies investigating the role of personality dimensions in PPD, research is needed on the efficacy and effectiveness of psychodynamic treatments 
for PPD. As Blum (2007) noted, there is only one study of the efficacy of psychoanalytic treatment of PPD, comparing it with cognitive-behavioral therapy, finding that both types of treatment are equally effective (Cooper et al., 2003). We hope that Blum's paper and this commentary contribute to increased research efforts to understand and treat PPD and related conditions.

This commentary, however, also illustrates that Blum (2007) underestimated the research contributions of psychoanalytic perspectives on PPD, possibly because he seems to have searched the literature using the descriptive term "postpartum depression." Psychoanalytic investigators, with considerable success, generally have taken a more dimensional approach toward the postpartum period, studying the transition to motherhood, focusing both on normal and deviant outcomes of this transition, including, but not limited to, depressive feelings and symptoms in the postpartum period.

On a more general note, it also seems that Blum mainly relied on a search of psychoanalytic journals. Psychoanalytically oriented research, however, is increasingly published in psychiatric and psychological journals. Thus, psychoanalytic researchers and clinicians should extend their literature searches beyond conventional psychoanalytic journals and include psychoanalytically inspired research published in main-stream journals in other disciplines, using broad ranging search engines such as PubMed that address a broad range of journals. The use of these broad ranging search engines cannot only amplify psychoanalytic understanding, but also establish communication with other disciplines, reducing the current "splendid isolation" of psychoanalysis.

Finally, as this commentary illustrates, cooperation and communication is needed between researchers and clinicians, between idiographic case studies and nomothetic group-oriented research, emphasizing the importance of the so-called "idiographicnomothetic-idiographic research cycles" in exploring psychoanalytic concepts (Luyten, Blatt, \& Corveleyn, 2006). Blum's (2007) paper and our comment attest to the potential constructive synergistic interaction of clinical case reports and systematic empirical investigations in more fully exploring important clinical issues.

\section{References}

Angyal, A. (1951). Neurosis and treatment: A holistic theory. New York: Wiley.

Anthony, E., \& Benedek, T. (Eds.). (1970). Parenthood, its psychology and psychopathology. New York: Little, Brown.

Antonucci, T. C., \& Mikus, K. (1988). The power of parenthood: Personality and attitudinal change during the transition to parenthood. In G. Y. Michaels \& W. A. Goldberg (Eds.), The transition to parenthood: Current theory and research (pp. 243-258). Cambridge, MA: Cambridge University Press.

Arendell, T. (2000). Conceiving and investigating motherhood: The decade's scholarship. Journal of Marriage and the Family, 62, 1192-1207.

Arieti, S., \& Bemporad, J. R. (1980). The psychological organization of depression. American Journal of Psychiatry, 137, 1360-1365.

Bagby, R. M., Kennedy, S. H., Dickens, S. E., Minifie, C. E., \& Schuller, D. R. (1997). Personality and symptom profiles of angry hostile depressed patient. Journal of Affective Disorders, 45, $155-160$.

Bakan, D. (1966). The duality of human existence: An essay on psychology and religion. Chicago: Rand McNally.

Beck, A. T. (1983). Cognitive therapy of depression: New perspectives. In P. J. Clayton \& J. E. Barrett (Eds.), Treatment of depression: Old controversies and new approaches (pp. 265-290). New York: Raven. 
Beck, C. (1996). Postpartum depressed mothers' experiences interacting with their children. Nursing Research, 45, 98-104.

Beck, C. (2002). Postpartum depression: A metasynthesis. Qualitative Health Research, 12, $453-$ 472.

Beebe, B. (2003). Brief mother-infant treatment: Psychoanalytically informed video-feedback. Infant Mental Health Journal, 24, 24-52.

Beebe, B. (2005). Mother-infant research informs mother-infant treatment. Psychoanalytic Study of the Child, 60, 7-46.

Beebe, B., Jaffe, J., Buck, K., Chen, H., Cohen, P., Blatt, S. J., et al. (2007). Six-week postpartum maternal self-criticism and dependency predict 4-month mother-infant self- and interactive regulation. Developmental Psychology, 43, 1360-1376.

Belsky, J., Rowine, M., \& Fish, M. (1989). The developing family system. In I. M. Gunnar (Ed.), Systems and development, Vol. 22, MN symposium on child psychology (pp. 119-166). Hillsdale, NJ: Erlbaum.

Benedek, T. (1959). Parenthood as a developmental phase: A contribution to the libido theory. Journal of the American Psychoanalytic Association, 7, 389-417.

Benoit, D., Parker, K. C. H., \& Zeanah, C. H. (1997). Mother's representations of their infants assessed prenatally: Stability and association with infant's attachment classification. Journal of Child Psychology and Psychiatry, 38, 307-313.

Besser, A. (2004). Self- and best-friend assessments of personality vulnerability and defenses in the prediction of depression. Social Behavior and Personality, 32, 559-594.

Besser, A., Flett, G. L., \& Davis, R. A. (2003). Self-criticism, dependency, silencing the self, and loneliness: A test of a mediational model. Personality and Individual Differences, 35, 17351752.

Besser, A., \& Priel, B. (2003a). Trait vulnerability and coping strategies in the transition to motherhood. Current Psychology, 22, 57-72.

Besser, A., \& Priel, B. (2003b). A multisource approach to self-critical vulnerability to depression: The moderating role of attachment. Journal of Personality, 71, 515-556.

Besser, A., \& Priel, B. (2005a). The apple does not fall far from the tree: Attachment styles and personality vulnerabilities to depression in three generations of women. Personality and Social Psychology Bulletin, 31, 1052-1073.

Besser, A., \& Priel, B. (2005b). Interpersonal relatedness and self-definition in late adulthood depression: Personality predispositions, and protective factors. Social Behavior and Personality, 33, 351-382.

Besser, A., Priel, B. (2007). Perceived social support, malevolent maternal representations, and older adults' depressed mood. Journal of Social and Clinical Psychology, 6, 728-750.

Besser, A., Priel, B., Flett, G. L., \& Wiznizer, A. (2007). Linear and nonlinear models of vulnerability to depression: Personality and postpartum depression in a high risk population. Individual Differences Research, 5, 1-29.

Besser, A., Priel, B., \& Wiznizer, A. (2002). Childbearing depressive symptomatology in high-risk pregnancies: The roles of working models and perceived spouse support. Personal Relationships, 9, 395-413.

Bibring, G. (1959). Some considerations of the psychological processes in pregnancy. The Psychoanalytic Study of the Child, 14, 113-121.

Bibring, G., Dwyer, T., Huntington, D., \& Valenstein, F. (1961). A study of the psychological processes in pregnancy and of the earliest mother-child relationship. I. Some propositions and comments. Psychoanalytic Study of the Child, 16, 9-24.

Blatt, S. J. (1974). Levels of object representation in anaclitic and introjective depression. Psychoanalytic Study of the Child, 29, 107-157.

Blatt, S. J. (1990). Interpersonal relatedness and self-definition: Two personality configurations and their implication for psychopathology and psychotherapy. In J. L. Singer (Ed.), Repression and dissociation: Implications for personality theory, psychopathology and health (pp. 299-335). Chicago: University of Chicago Press. 
Blatt, S. J. (1991). A cognitive morphology of psychopathology. Nervous and Mental Disease, 179, 449-458.

Blatt, S. J., \& Homann, E. (1992). Parent-child interaction in the etiology of dependent and self-critical depression. Clinical Psychology Review, 12, 47-91.

Blatt, S. J. (1998). Contributions of psychoanalysis to the understanding and treatment of depression. Journal of the American Psychoanalytic Association, 46, 722-752.

Blatt, S. J. (2004). Experiences of depression: Theoretical, clinical and research perspectives. Washington, DC: American Psychological Association.

Blatt, S. J. (2006). A fundamental polarity in psychoanalysis: Implications for personality development, psychopathology, and the therapeutic process. Psychoanalytic Inquiry, 26, 492-518.

Blatt, S. J. (2008). Polarity of experience: Relatedness and self-definition in personality development, psychopathology and the therapeutic process. Washington, DC: American Psychological Association.

Blatt, S. J., \& Blass, R. (1990). Attachment and separateness: A dialectic model of the products and processes of psychological development. The Psychoanalytic Study of the Child, 45, 107-127.

Blatt, S. J., \& Blass, R. (1996). Relatedness and self definition: A dialectic model of personality development. In G. G. Noam \& K. W. Fischer (Eds.), Development and vulnerabilities in close relationships (pp. 309-338). Hillsdale, NJ: Erlbaum.

Blatt, S. J., D’Afflitti, J. P., \& Quinlan, D. M. (1976). Experiences of depression in normal young adults. Journal of Abnormal Psychology, 85, 383-389.

Blatt, S. J., Quinlan, D. M., Chevron, E. S., McDonald, C., \& Zuroff, D. C. (1982). Dependency and self-criticism: Psychological dimensions of depression. Journal of Counseling and Clinical Psychology, 150, 113-124.

Blatt, S. J., \& Shichman, S. (1983). Two primary configurations of psychopathology. Psychoanalysis and Contemporary Thought, 6, 187-254.

Blatt, S. J., Zohar, A. H., Quinlan, D. M., Zuroff, D. C., \& Mongrain, M. (1995). Subscales within the dependency factor of the depressive experiences questionnaire. Journal of Personality Assessment, 64, 319-339.

Blatt, S. J., \& Zuroff, D. C. (1992). Interpersonal relatedness and self-definition: Two prototypes for depression. Clinical Psychology Review, 12, 527-562.

Blum, H. P. (1978). Reconstruction in a case of postpartum depression. Psychoanalytic Study of the Child, 33, 335-362.

Blum, L. D. (2007). Psychodynamics of postpartum depression. Psychoanalytic Psychology, 24, 45-62.

Born, L., \& Steiner, M. (1999). Irritability: The forgotten dimension of female-specific mood disorders. Archives of Women's Mental Health, 2, 153-167.

Boyce, P., Parker, G., Barnett, S., Cooney, M., \& Smith, F. (1991). Personality as a vulnerability factor to depression. British Journal of Psychiatry, 159, 106-114.

Brazelton, T. B., \& Cramer, B. (1991). The earliest relationship: Parents, infants and the drama of early attachment. London: Karnak.

Brooks-Gunn, J., \& Chase-Lansdale, P. L. (1995). Adolescent parenthood. In M. H. Bornstein (Ed.). Handbook of parenting: Vol. 3. Status and social conditions of parenting. (pp. 113-149). Mahwah, NJ: Erlbaum.

Brown, G. W., \& Harris, T. (1978). Social origins of depression. New York: Free Press.

Cohen, L. J., \& Slade, A. (2000). The psychology and the psychopathology of pregnancy: Reorganization and transformation. In C. H. Zeanah (Ed.), Handbook of infant mental health (2nd ed., pp. 20-36). New York: Guilford Press.

Cohen, M. H. (1993). The unknown and the unknowable: Managing sustained uncertainty. Western Journal of Nursing Research, 15, 77-95.

Colletta, N. D., \& Gregg, C. H. (1981). Adolescent mothers' vulnerability to stress. Journal of Nervous and Mental Disease, 169, 50-54.

Condon, J. T. (1993). The assessment of antenatal emotional attachment: Development of a questionnaire instrument. British Journal of Medical Psyconchology, 66, 167-183. 
Cooper, P. J., Murray, L., Wilson, A., \& Romaniuk, H. (2003). Controlled trial of the short- and long-term effect of psychological treatment of post-partum depression. I. Impact on maternal mood. British Journal of Psychiatry, 182, 412-419.

Cowan, C. P., \& Cowan, P. A. (1992). When partners become parents: The big life change for couples. New York: Harper Collins.

Cramer, B. (1997). Psychodynamic perspectives on the treatments of postnatal depression. In L. Murray \& P. J. Cooper (Eds.), Postpartum depression and child development. London: Guilford Press.

Cross, S. E., \& Madson, L. (1997). Models of the self: Self-construals and gender. Psychological Bulletin, 122, 5-37.

Cummings, E. M., \& Davies, P. T. (1994). Maternal depression and child development. Journal of Child Psychology and Psychiatry, 35, 73-112.

Emanuel, L. (2006). A slow unfolding - at double speed: Reflections on ways of working with parents and their young children within the Tavistock Clinic's Under Five Service. Journal of Child Psychotherapy, 32, 66-84.

Espasa, F. (2004). Parent-infant psychotherapy, the transition to parenthood and parental narcissism: Implications for treatment. Journal of Child Psychotherapy, 30, 155-171.

Feder, L. (1980). Preconceptive ambivalence and external reality. International Journal of Psychoanalysis, 61, 161-178.

Ferber, S., \& Feldman, R. (2005). Delivery pain and the development of mother-infant interaction. Infancy, 8, 43-62.

Fisher, S., \& Greenberg, R. P. (1996). Freud scientifically reappraised. Testing the theories and therapy. New York: Wiley.

Fonagy, P., Gergely, G., \& Target, M. (2007). The parent-infant dyad and the construction of the subjective self. Journal of Child Psychology and Psychiatry, 48, 288-328.

Fonagy, P., Steele, H., \& Steele, M. (1991). Maternal representations of attachment during pregnancy predict the organization of infant-mother attachment at one year of age. Child Development, 62, 891-905.

Fraiberg, S. (1980). Clinical studies in infant mental health: The first year of life. New York: Basic Books.

Fraiberg, S. H., Adelson, E., \& Shapiro, V. (1975). Ghosts in the nursery: A psychoanalytic approach to the problem of impaired infant-mother relationships. Journal of the American Academy Child Psychiatry, 14, 387-422.

Franche, R. L. (2001). Psychologic and obstetric predictors of couples' grief during pregnancy after miscarriage or perinatal death. Obstetrics \& Gynecology, 97, 597-602.

Franche, R. L., \& Mikail, S. F. (1999). The impact of perinatal loss on adjustment to subsequent pregnancy. Social Science and Medicine, 48, 1613-1623.

Freud, S. (1930/1961). Civilization and its discontents. In S. J. London (Ed.), The standard ed. of the complete psychological works of Sigmund Freud (pp. 64-145). London: Hogarth.

Gilbert, P., Gilbert, J., \& Irons, C. (2004). Life events, entrapments and arrested anger in depression. Journal of Affective Disorders, 79, 149-160.

Gotlib, I. H., \& Hooley, J. M. (1988). Depression and marital functioning: Current status and future directions. In S. Duck (Ed.), Handbook of personal relationships: Theory, research and intervention (pp. 543-570). Chichester, UK: Wiley.

Hagen, E. H. (1999). The functions of postpartum depression. Evolution and Human Behavior, 20, 325-359.

Halberstadt-Freud, H. C. (1993). Postpartum depression and symbiotic illusion. Psychoanalytic Psychology, 10, 407-423.

Hoffman, L. (2003). Mothers' ambivalence with their babies and toddlers: Manifestations of conflicts with aggression. Journal of the American Psychoanalytic Association, 51, 1219-1240.

Hopkins, J., Marcus, M., \& Campbell, S. B. (1984). Postpartum depression: A critical review. Psychological Bulletin, 95, 498-515. 
Kestenberg, J. (1956). On the development of maternal feelings in early childhood- observations and reflections. Psychoanalytic Study of the Child, 11, 257-291.

Lazarus, R. S. (1999). Stress and emotion: A new synthesis. New York: Springer.

Leckman, J., Feldman, R., Swain, J., Eicher, V., Thompson, N., \& Mayes, L. (2004). Primary parental preoccupation: Circuits, genes, and the crucial role of the environment. Journal of Neural Transmission, 111, 753-771.

Leckman, J., \& Herman, A. (2002). Maternal behavior and developmental psychopathology. Biological Psychiatry, 51, 27-43.

Leckman, J., Mayes, L., Feldman, R., Evans, D., King, R. A., \& Cohen, D. J. (1999). Early parental preoccupations and behaviors and their possible relationship to the symptoms of obsessivecompulsive disorder. Acta Psychiatrica Scandinavica, 100(Suppl. 396), 1-26.

Leckman, J. F., Feldman, R., Swain, J. E., \& Mayes, L. C. (2007). Primary parental preoccupation: Revisited. In L. C. Mayes, P. Fonagy \& M. Target (Eds.), Developmental science and psychoanalysis: Integration and innovation. London: Karnac Books.

Likierman, M. (2003). Post natal depression, the mother's conflict and parent-infant psychotherapy. Journal of Child Psychotherapy, 29, 301-315.

Luyten, P., Blatt, S. J., \& Corveleyn, J. (2005). Towards integration in the theory and treatment of depression? The time is now. In J. Corveleyn, P. Luyten \& S. J. Blatt (Eds.), The theory and treatment of depression: Towards a dynamic interactionism model (pp. 265-296). Leuven/ Mahwah, NJ: Leuven University Press/Erlbaum.

Luyten, P., Blatt, S. J., \& Corveleyn, J. (2006a). Minding the gap between positivism and hermeneutics in psychoanalytic research. Journal of the American Psychoanalytic Association, 54, 571-610.

Luyten, P., Blatt, S. J., Van Houdenhove, B., \& Corveleyn, J. (2006b). Depression research and treatment: Are we skating to where the puck is going to be? Clinical Psychology Review, 26, 985-999.

Luyten, P., Sabbe, B., Blatt, S. J., Meganck, S., Jansen, B., De Grave, C., et al. (2007). Dependency and self-criticism: Relationship with major depressive disorder, severity of depression and clinical presentation. Depression \& Anxiety, 24, 586-596.

Mammen, O. K., Shear, M. K., Pilkonis, P. A., Kolko, D. J., Thase, M. E., \& Greeno, C. G. (1999). Anger attacks: Correlates and significance of an underrecognized symptom. Journal of Clinical Psychiatry, 60, 633-642.

McAdams, D. (1985). Power, intimacy and the life story: Personological inquiries into identity. New York: Guilford Press.

McClelland, D. C. (1985). Human motivation. Gleview, IL: Scott Foresman.

McDonough, S. (2000). Interaction guidance: An approach for difficult-to-engage parents. In C. Zeanah (Ed.), Handbook of infant mental health (pp. 485-493). New York/London: The Guilford Press.

Menos, M. D., \& Wilson, A. (1998). Affective experiences and levels of self-organization in maternal postpartum depression. Psychoanalytic Psychology, 15, 396-419.

Nelson, W. E. (1987). Nelson's textbook of pediatrics (13th ed.). Philadelphia: W. B. Saunders.

Nietzel, M. T., \& Harris, M. J. (1990). Relationship of dependency and achievement/autonomy to depression. Clinical Psychology Review, 10, 279-297.

Pines, D. (1972). Pregnancy and motherhood. Interaction between fantasy and reality. British Journal of Medical Psychology, 45, 333-343.

Pines, D. (1988). Adolescent pregnancy and motherhood: A psychoanalytical perspective. Psychoanalytic Inquiry, 8, 234-251.

Pines, D. (1990). Pregnancy, miscarriage and abortion. A psychoanalytic perspective. International Journal of Psycho-Analysis, 71, 301-307.

Ponirakis, A., Susman, E. J., \& Stifter, C. A. (1998). Negative emotionality and cortisol during adolescent pregnancy and its effects on infant health and autonomic nervous system reactivity. Developmental Psychobiology, 33, 163-174.

Priel, B., \& Besser, A. (1999). Vulnerability to postpartum depressive symptomatology: Depen- 
dency, self-criticism and the moderating role of antenatal attachment. Journal of Social and Clinical Psychology, 18, 240-253.

Priel, B., \& Besser, A. (2000a). Adult attachment styles, early relationships, antenatal attachment and perceptions of infant temperament: A study of first-time mothers. Personal Relationship, 7 , 291-310.

Priel, B., \& Besser, A. (2000b). Dependency and self-criticism among first-time mothers: The roles of global and specific support. Journal of Social and Clinical Psychology, 19, 437-450.

Priel, B., \& Besser, A. (2001). Bridging the gap between attachment and object relations' theories: A study of the transition to motherhood. British Journal of Medical Psychology, 74, 85-100.

Priel, B., \& Besser, A. (2002). Perceptions of early relationships during the transition to motherhood: The mediating role of social support. Infant Mental Health Journal, 23, 343-360.

Priel, B., \& Cantor, B. (1988). The influence of high risk pregnancies and social support systems on maternal perceptions of the infant. Infant Mental Health Journal, 9, 235-244.

Raphaël-Leff, J. (1982). Psychotherapeutic needs of mothers to be. Journal of Child Psychotherapy, 8, 3-13.

Raphaël-Leff, J. (1986). Facilitators and regulators: Conscious and unconscious processes in pregnancy and early motherhood. British Journal of Medical Psychology, 59, 43-55.

Raphaël-Leff, J. (2000). Climbing the walls: Therapeutic intervention for post-partum disturbance. In J. Raphaël-Leff (Ed.), Spilt milk. London: Institute of Psychoanalysis.

Raphaël-Leff, J. (2001). Psychological processes of childbearing (Rev. ed.) London: Chapman \& Hall.

Rosenblum, O., Mazet, P., \& Bénony, H. (1997). Mother and infant involvement states and maternal depression. Infant Mental Health Journal, 18, 350-363.

Ruble, D. N., Brooks-Gunn, J., Fleming, A. S., Fitzmaurice, G., Stangor, C., \& Deutsch, F. (1990). Transition to motherhood and the self: Measurement, stability and change. Journal of Personality and Social Psychology, 58, 450-463.

Ruddick, S. (1994). Thinking mothers/conceiving birth. In M. H. D. Bassin \& M. M. Kaplan (Eds.), Representations of motherhood (pp. 29-46). New Haven, CT: Yale University Press.

Shahar, G. (2006). Clinical action: Introduction to the special section on the action perspective in clinical psychology. Journal of Clinical Psychology, 62, 1053-1064.

Shirilla, J., \& Weatherston, D. (Eds.). (2002). Case studies in infant mental health. Risk, resiliency, and relationships. Washington, DC: Zero To Three.

Stern, D. (1995). The motherhood constellation. A unified view of parent-infant psychotherapy. New York: Basic Books.

Swendsen, J. D., \& Mazure, C. M. (2000). Life stress as a risk factor for postpartum depression: Current research and methodological issues. Clinical Psychology: Science and Practice, 7, $17-31$.

Terry, D. J. (1991). Coping resources and situational appraisals as predictors of coping behavior. Personality and Individual Differences, 12, 1031-1047.

Terry, D. J., Mayocchi, L., \& Hynes, G. J. (1996). Depressive symptomatology in new mothers: A stress and coping perspective. Journal of Abnormal Psychology, 105, 220-231.

Tracey, N. (2000). Thinking about and working with depressed mothers in the early months of their infant's life. Journal of child psychotherapy, 26, 183-207.

Van den Bergh, B., \& Marcoen, A. (2004). High antenatal maternal anxiety is related to ADHD symptoms, externalizing problems, and anxiety in 8- and 9- year-olds. Child Development, 75, 1085-1097.

Van den Bergh, B., Mennes, M., Oosterlaan, J., Stevens, V., Stiers, P., Marcoen, A., et al. (2005). High antenatal maternal anxiety is related to impulsivity during performance on cognitive tasks in 14- and 15-year-olds. Neuroscience Biobehavior Review, 29, 259-269.

Vliegen, N. (2006). She doesn't want to look at me. Mother-infant observation as a bridge between clinical practice and research. Infant Observation, 9, 261-268.

Vliegen, N., \& Luyten, P. (in press). The role of dependency and self-criticism in the relationship between postpartum depression and anger. Personality and Individual Differences. 
Vliegen, N., \& Luyten, P. (2007a). Dependency and self-critical perfectionism in postpartum depression and anxiety: A case-control study. Manuscript submitted for publication.

Vliegen, N., \& Luyten, P. (2007b). Personality and the balance between positive and negative affect in postpartum depression. Manuscript submitted for publication.

Vliegen, N., \& Luyten, P. (2007c). Maternal affective dynamics and Emotional Availability in the postpartum period: A multi-method study in postpartum depressed and normal young mothers. Manuscript in preparation.

Vliegen, N., Luyten, P., Meurs, P., \& Cluckers, G. (2006). Adaptive and maladaptive dimensions of relatedness and autonomy: Relationship with postpartum anxiety and depression. Personality and Individual Differences, 41, 395-406.

Watillon, A. (1993). The dynamics of psychoanalytic therapies of the early parent-child relationship. International Journal of Psychoanalysis, 74, 1037-1048.

Weinberg, M. K., \& Tronick, E. Z. (1998). The impact of maternal psychiatric illness on infant development. Journal of Clinical Psychiatry, 59(Suppl. 2), 53-61.

Whiffen, V. E., \& Gotlib, I. H. (1993). Comparison of postpartum and non-postpartum depression: Clinical presentation, psychiatric history and psychosocial functioning. Journal of Consulting and Clinical Psychology, 61, 485-494.

Winnicott, D. W. (1956). Primary maternal preoccupation. In D. W. Winnicott (Ed.), Collected papers: Through paediatrics to psycho-analysis (pp. 300-305). London: Tavistock.

Winter, D. (1973). The power motive. New York: Free Press.

Zuroff, D. C., Mongrain, M., \& Santor, D. A. (2004). Conceptualizing and measuring personality vulnerability to depression: Comment on Coyne and Whiffen (1995). Psychological Bulletin, 130, 489-511. 